\title{
APPLICATION OF AHP METHOD FOR MAPPING SLOPE GEOMORPHIC PHENOMENA
}

\author{
Prof. Dr. Adrian Grozavu ${ }^{1}$ Dr. Cristian Valeriu Patriche ${ }^{2}$ Dr. Florin Constantin Mihai ${ }^{1}$ \\ 1 'Alexandru Ioan Cuza University' of Iasi, Romania \\ ${ }^{2}$ Romanian Academy, Iasi Branch, Geography Team, Romania
}

Preprint version - citation: Grozavu., A., Patriche C.V., Mihai, FC., 2017. Application of AHP method for mapping slope geomorphic phenomena. 17th International Multidisciplinary Scientific Geoconference. Conference Proceedings (vol 17) on INFORMATICS, GEOINFORMATICS AND REMOTE SENSING (Issue 23) pp.377 384 doi: $10.5593 /$ sgem2017/23/S11.046

\begin{abstract}
Landslides are common and frequent geomorphic phenomena for the plateau regions in Romania having important consequences, especially economic ones, that needs designing scientific and technical plans for landslide risk mitigation. For this, an important preliminary step is assessing and mapping the landslide susceptibility. This paper examines a plateau zone in eastern Romania providing such a map, based on the landslides inventory, the digital elevation model (DEM) and the thematic layers of several factors thought to be potential predictors of landslides occurrence: topographic features, land use, and lithology. The methodological framework is based on the analytical hierarchy process (AHP) principles and factors weights attributed based on frequency of landslides. The predictive performance of the model was assessed using the confusion matrix, the ROC (receiver operating characteristic) curve and the AUC (area under curve) parameter. The results indicate a good correspondence between the susceptibility estimated for the test samples and for the validation samples.
\end{abstract}

Keywords: landslide susceptibility, analytic hierarchy process (AHP), Bârlad Plateau

\section{INTRODUCTION}

The ascendent trend of human pressure on territories with different degrees of sensitivity and the activity of geomorphic processess of recent years impose the multiplication of the number of works dedicated to landslides. Due their important consequences both economic and ecological there is a need in designing scientific and technical plans for landslide risk mitigation by taking into consideration the hazard, susceptibility and vulnerability components.

In this idea, assessing and mapping the landslide susceptibility is an important preliminary step. The methodological framework benefits from the generalization of geographical information systems (GIS), the spectacular increase in aquisition of spatial data, especially through satelite images, and, of course, the development of statistical models explaining and forecasting such phenomena.

As evidenced by scientific literature, the landslide susceptibility can be assessed by applying various methods [1]: qualitative (like ranking and rating), quantitative (like bivariate and multivariate statistical analyses), and hybrid methods (combining the two 
categories). Among the qualitative methods (more precisely, semi-qualitative) is analytical hierarchy process (AHP) method, developed for solving decision-making problems [2]. Many specialized studies have used the AHP method for assessing the landslide susceptibility with good results $[3,4,5,6,7,8$, 9]. In Romania, several recent studies may be mentioned $[10,11]$ which aimed at assessing landslide susceptibility by applying this method.

The purpose of this paper is to identify, weigh and integrate different parameters that determine the landslide susceptibility in a plateau region from Eastern Romania, where important areas are affected by geomorphological processes, including landslides. It was intended to test the hypothesis that the application of the AHP method can lead to good results when supported by good geomorphological expertise.

\section{STUDY AREA}

Located in eastern Romania and covering an area of about $9100 \mathrm{~km}^{2}$, the Bârlad Plateau corresponds to the central and southern parts of the Moldavian Plateau (Fig. 1).



Figure 1. The Bârlad Plateau - location in Romania and landslide inventory

Surface sedimentary strata have a monocline arrangement being represented by Sarmatian and Pliocene formations, such as clays, marls, sands, with important intercalations of sandstones and limestones. The relief is formed by massive hills and plateaus registering the highest altitudes $(556 \mathrm{~m})$ in the northern part, while in the southern part are characteristic long hills, separated by relatively parallel valleys registering the lowest altitudes $(6 \mathrm{~m})$.

The network of small subsequent rivers, tributaries of the main rivers, contributes to the sculpting of cuestas, asymmetric interfluves. 
Steeper slopes sectors are frequently affected by geomorphological processes, such as landslides and gullying. The climate of the Bârlad Plateau is temperate continental, with average temperatures of $7.8-10.2^{\circ} \mathrm{C}$ and yearly rainfall of $490-700 \mathrm{~mm}$. Land use is dominated by arable land, followed by pastures, and hayfields and forests.

\section{MATERIALS AND METHODS}

Modelling terrain susceptibility to landslides and, implicitly, getting its map, started with preparation of a GIS database comprising the landslide inventory, the digital elevation model (DEM) and the thematic layers of several factors thought to be potential predictors of landslides occurrence.

The landslide inventory (Fig. 1) was created as polygonal data using aerial images (0.5 meters resolution), topographic maps (1:25,000 scale) and selective field surveys. All types of landslides have been considered, with a number of 5718 cases being identified, totaling an area of 37,642 hectares (4.14 \% of the study area). The size of landslides varies between 0.01 and 266.2 hectares, with an average area of 6.5 hectares. Considering the way of manifestation, landslides are both translational (with depths of 3-4 $\mathrm{m}$ ) and rotational (with depths over $5 \mathrm{~m}$ ).

Thematic layers were prepared for five factors that we consider relevant for landslide manifestation in the entire region of the Moldavian Plateau [11]: altitude, slope, aspect, land use, and lithology (Fig. 2).

Furthermore, in order to obtain the landslide susceptibility index (LSI), data were processed by applying the AHP principles. AHP method is a multi-criteria decision making tool useful to find suitable alternatives also for landslide susceptibility. It offers a matrix model of integrating indicators, based on the systemic interpretation by pairwise comparison of a list of factors by means of predefined scores (from 1 to 9) indicating their relative importance. In order to ensure that the weighting of the criteria pair-wise is not random, AHP incorporates the calculus of consistency ratio that should be inferior to 0.1 .

The application of AHP methodology is based on previous research on the Bârlad Plateau [11]. The weights of the five previously selected factors were assigned on the basis of frequency of landslides [4]. For this purpose, the factors were classified and landslide densities were computed for each class, using the formula:

$$
L D_{i}=\frac{L A_{i} / A_{i}}{L A / A}
$$

where $L D_{i}$ is the landslide density value for class $i, L A_{i}$ and $A_{i}$ are the landslide area and the total area of class $i$, respectively, $L A$ and $A$ are the total landslide area and the total area of the study region, respectively.

The landslide densities were normalized between 0 and 1 and these normalized values were used as the class weights for APH procedure:

$$
L D_{i(0-1)}=\frac{L D_{i}-L D_{\min }}{L D_{\max }-L D_{\min }}
$$

where $L D_{\mathrm{i}(0-1)}$ is the normalized landslide density value for class $i, L D_{\mathrm{i}}$ is the initial landslide density value for class $i$, and $L D_{\min }$ and $L D_{\max }$ are the minimum and maximum density values for the factor, respectively. 
The factor weights were derived from a pair-wise comparison matrix, with a consistency ratio of 0.01 , which was previously selected from four such matrices [11]. The matrix gives the highest weight to slope factor, followed by aspect and land use, with the same weight, then by lithology and altitude (Table 1).

a)



c)

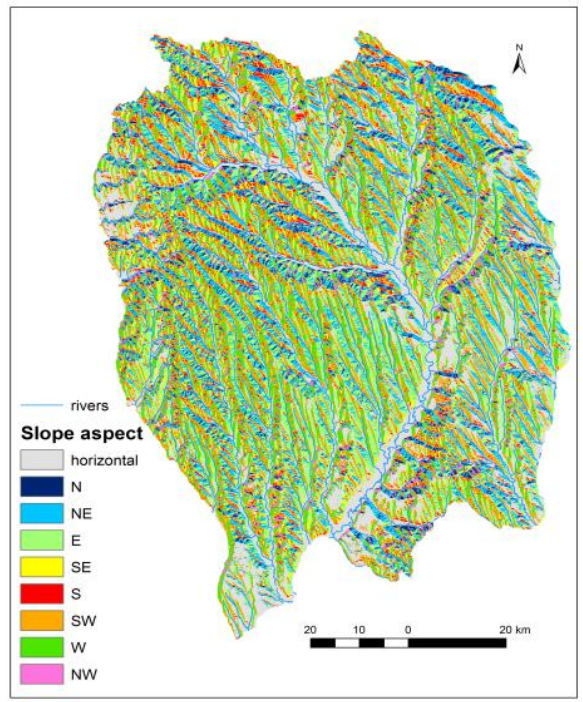

e) b)



d)

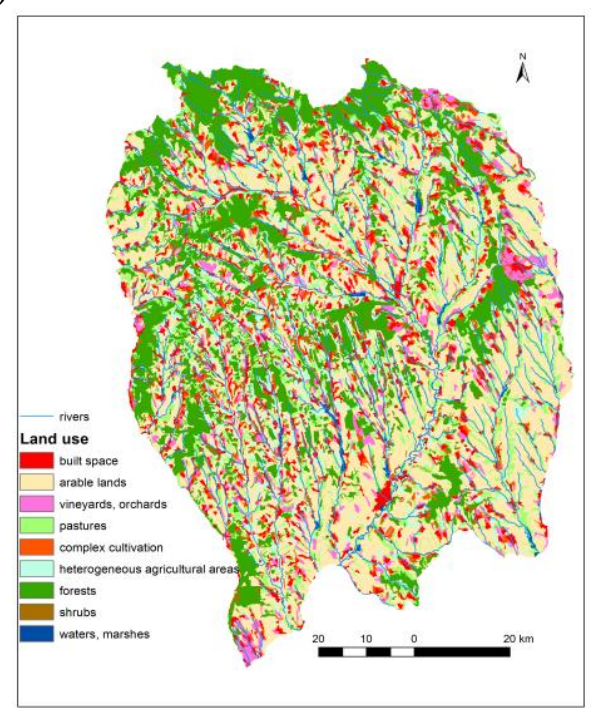




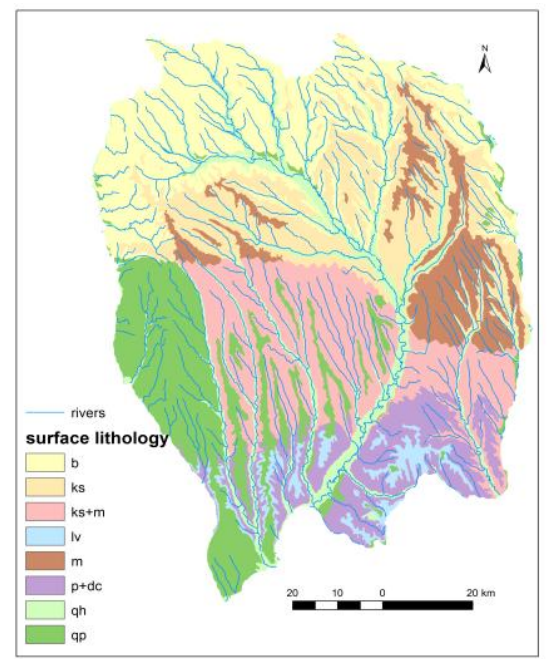

B - Bassarabian

Ks - Kersonian

ks+m - Kersonian+Miocene

Iv - Levantin

m - Meotian

p+dc - Pontian+Dacian

qp - Pleistocene

qh - Holocene

Figure 2. Selected predictors for AHP analysis: $\mathrm{a}$ - altitude; $\mathrm{b}$ - slope; $\mathrm{c}$ - aspect; $\mathrm{d}$ - land use; e - lithology

Table 1. Pair-wise comparison matrix and factor weights

\begin{tabular}{|l|l|l|l|l|l|l|}
\hline & Altitude & Slope & Aspect & Lithology & Land use & Factor weight \\
\hline Altitude & 1 & 0.1428 & 0.2 & 0.3333 & 0.2 & $\mathbf{0 . 0 4 6 1 6}$ \\
\hline Slope & 7 & 1 & 2 & 2 & 2 & $\mathbf{0 . 3 6 9 5 2}$ \\
\hline Aspect & 5 & 0.5 & 1 & 2 & 1 & $\mathbf{0 . 2 2 5 1 1}$ \\
\hline Lithology & 3 & 0.50 & 0.5 & 1 & 0.5 & $\mathbf{0 . 1 3 4 1 0}$ \\
\hline Land use & 5 & 0.5 & 1 & 2 & 1 & $\mathbf{0 . 2 2 5 1 1}$ \\
\hline
\end{tabular}

Having factor weights and class weights, the LSI was computed as follows:

$$
L S I=\sum_{i=1}^{5} F W_{i} \times C W_{i}
$$

where $F W_{i}$ and $C W_{i}$ are the factor weights and the class weights for factor $i$.

The landslide susceptibility values were classified into five classes (very low, low, medium, high and very high susceptibility), using Jenks natural break and standard deviation algorithms.

Finally, the percentages of landslide area falling into the high and very high landslide susceptibility classes were used to validate the AHP model. In addition, the confusion matrix and the ROC (receiver operating characteristic) curve were computed and used for validation purposes. In order to perform the latter type of validation, two approximately equal samples of points were generated inside and outside the landslide area.

\section{RESULTS AND DISCUSSION}

Applying AHP method allowed us to estimate areas where landslides may occur in the future, and Figure 3 shows the map of landslide susceptibility classes obtained for the study area. 
The landslide density values computed for the five considered factors reveal that, in Bârlad Plateau, the highest density of landslides is associated with middle-high altitudes (250-300m), higher slope values $\left(9-12^{\circ}\right)$, northern and north-western aspects, Bassarabian and Kersonian deposits and pastures.

The LSI varies between 0 and 1 , with an average of 0.34 and a standard deviation of 0.2. The comparison of LSI classes (Table 2) showed that the standard deviation procedure is slightly better suited for class separation, compared to the natural breaks method, because more landslide area is included in the high and very high susceptibility classes $(85.9 \%$, compared to $82.5 \%)$.

The standard deviation classified LSI (Fig. 4) reveals that most of the Bârlad Plateau has low and moderate susceptibility for landslides, these classes grouping $35.1 \%$ $\left(3189 \mathrm{~km}^{2}\right)$ and $31.1 \%\left(2823 \mathrm{~km}^{2}\right)$ respectively, of the total area. The high susceptibility class is quite extended, representing almost a quarter of the total study area $(22.6 \%$, $\left.2048 \mathrm{~km}^{2}\right)$. The very high susceptibility class groups $9.3 \%$ of the study area $\left(842 \mathrm{~km}^{2}\right)$, while the very low susceptibility class has the lowest share $\left(1.8 \%, 167 \mathrm{~km}^{2}\right)$, including flat alluvial plains of the main rivers.

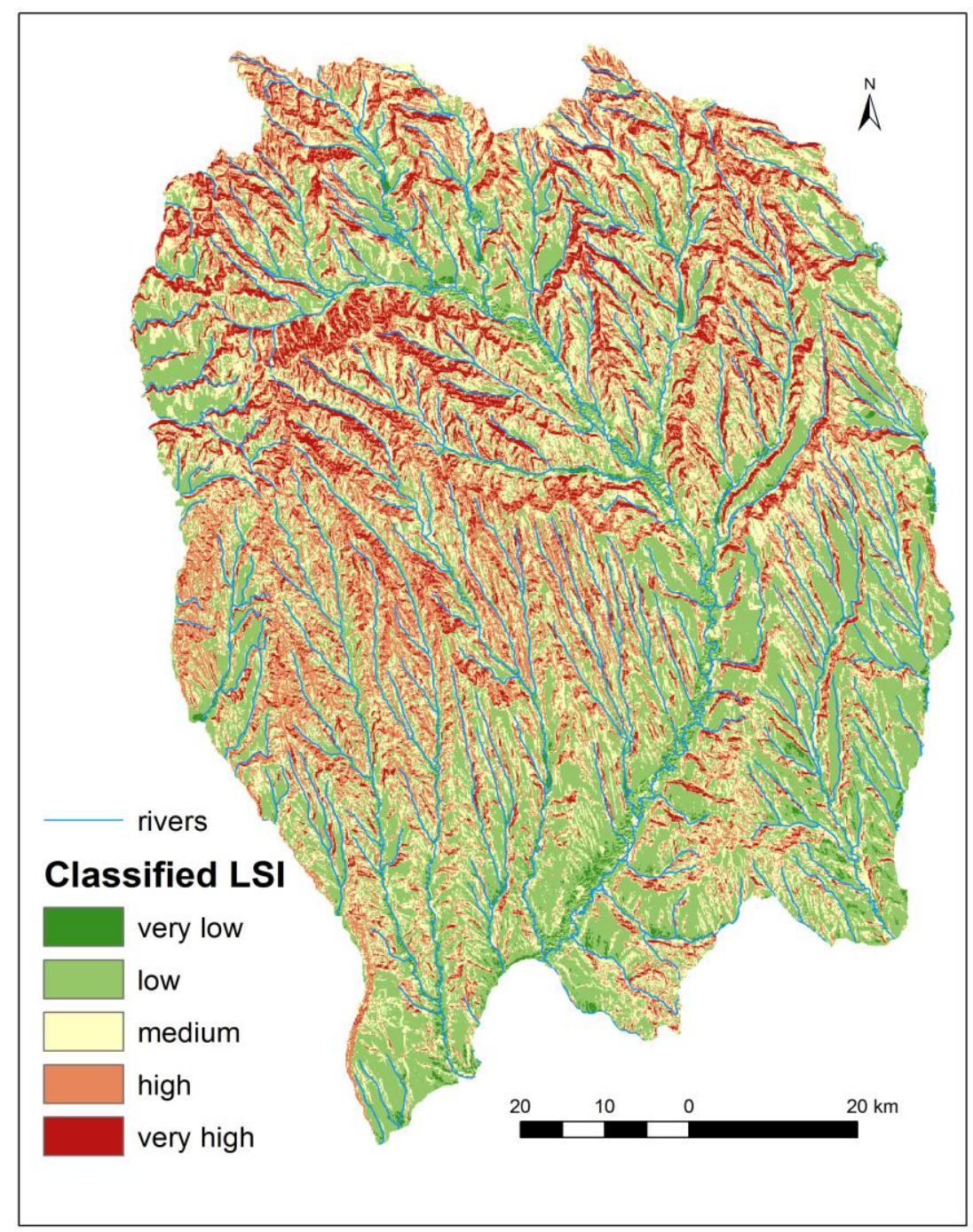

Figure 3. Landslide susceptibility classes in Bârlad Plateau 
Table 2. Areas and shares of landslide susceptibility classes inside landslide area

\begin{tabular}{|l|l|l|l|l|l|l|}
\hline \multirow{2}{*}{ Class name } & \multicolumn{3}{|c|}{ Natural breaks method } & \multicolumn{3}{c|}{ Standard deviation method } \\
\cline { 2 - 7 } & $\begin{array}{c}\text { LSI } \\
\text { threshold }\end{array}$ & $\begin{array}{c}\text { Landslide } \\
\text { area }\left(\mathrm{km}^{2}\right)\end{array}$ & $\begin{array}{c}\% \text { of landslide } \\
\text { area }\end{array}$ & $\begin{array}{c}\text { LSI } \\
\text { threshold }\end{array}$ & $\begin{array}{c}\text { Landslide } \\
\text { area }\left(\mathrm{km}^{2}\right)\end{array}$ & $\begin{array}{c}\text { \% of landslide } \\
\text { area }\end{array}$ \\
\hline Very low & $<0.171$ & 0.922 & 0.24 & $<0.04$ & 0.045 & 0.01 \\
\hline Low & $0.171-0.313$ & 11.750 & 3.13 & $0.04-0.24$ & 4.000 & 1.07 \\
\hline Medium & $0.313-0.463$ & 52.806 & 14.06 & $0.24-0.44$ & 48.653 & 12.96 \\
\hline High & $0.463-0.626$ & 123.898 & 33.00 & $0.44-0.64$ & 149.945 & 39.93 \\
\hline Very high & $>0.626$ & 186.112 & 49.57 & $>0.64$ & 172.845 & 46.03 \\
\hline
\end{tabular}

As already mentioned, the evaluation of predictive performance of the applied model was done using the confusion matrix and the ROC curve. The confusion matrix includes the numbers and percentages of correctly and incorrectly classified landslide and nonlandslide points for a cut-off LSI value of 0.5 . The point validation presented in Table 3 shows that $74.67 \%$ of the non-landslide points and $80.29 \%$ of the landslide points were correctly classified, the overall accuracy being $77.49 \%$.



Figure 4. Histogram of LS classes separated by standard deviation procedure

The ROC curve is a graphic representation of true positive rate (also known as sensitivity) against the false positive rate (also known as 1 - specificity) for all possible cut-off values.

Table 3. Confusion matrix of AHP model

\begin{tabular}{c|ll|c|c}
\hline from $\backslash$ to & 0 & 1 & Total & $\%$ correct \\
\hline 0 & 4428 & 1502 & 5930 & $74.67 \%$ \\
1 & 1182 & 4814 & 5996 & $80.29 \%$ \\
\hline Total & 5610 & 6316 & 11926 & $77.49 \%$ \\
\hline
\end{tabular}

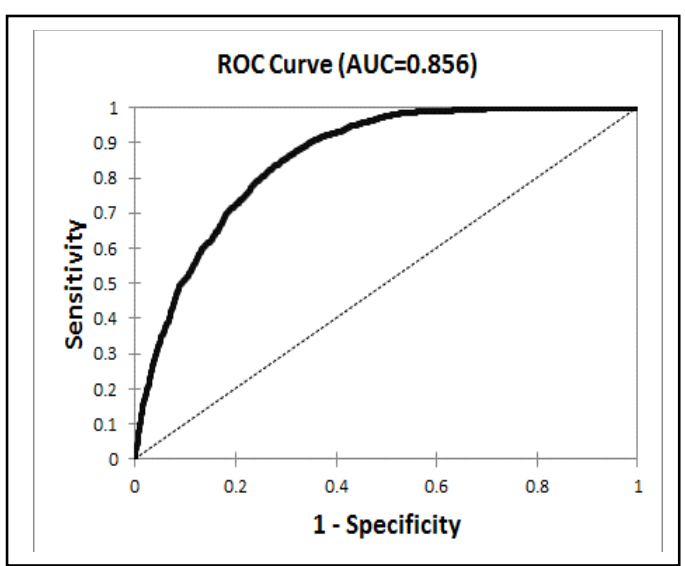

Figure 5. The ROC curve and AUC parameter for AHP model 
The area under the ROC curve (AUC) is an indicator of model quality. Generally, a good model has an AUC value of 0.7 - 0.9, while an excellent model has values over 0.9. The AUC parameter (0.856) shows that the AHP model is good and capable of predicting landslide occurrences with sufficient accuracy.

\section{CONCLUSIONS}

Assessing the probability of landslide occurrence is mandatory phase for an adequate landslide risk management. Identifying the significant factors that favor or trigger the sliding processes is of the highest importance. In this context, the AHP method proves to be a useful tool that guarantees good results although it is considered as a subjective approach, that takes into account the expert knowledge. It is really difficult to rank the relative importance of the landsliding factors, because they are often closely related to one another. For instance, in the case of our region, slope and aspect are well correlated. Steeper slopes are associated with north, north-west and north-east expositions due to the monocline structure of the surface geological strata. The subjectivity of AHP is an advantage when the expertise on these geomorphological processes is good and mapping of landslide susceptibility is less expensive stage in the challenge of controlling their risk.

\section{REFERENCES}

[1] Mărgărint M.C., Grozavu A., Patriche C.V., Assessing the spatial variability of coefficients of landslide predictors in different regions of Romania using logistic regression, Nat Hazards Earth Syst Sci, vol. 13, pp. 3339-3355, 2013;

[2] Saaty T.L., The Analytical Hierarchy Process, McGraw Hill, New York, 2000.

[3] Ayalew L., Yamagishi H., Marui H., Kanno T., Landslides in Sado Island of Japan: Part II. GIS-based susceptibility mapping with comparisons of results from two methods and verifications, Eng Geol, vol. 81, pp 432-445, 2005;

[4] Bai S.B., Zhou P.G., Wang J., Hou S.S., Lu G.N., Zhang F.Y., GIS-based susceptibility mapping with comparisons of results from analytical hierarchy process versus logistic regression in the Three Gorges Area, China. In Chen Z., Zhang J., Li Z., Wu F., Ho K. (eds.) Landslides and Engineered Slopes - From the Past to the Future, vol. 2, pp. 1067-1070, CRC Press, Balkema, 2008;

[5] Günther A., Reichenbach P., Malet J.P., Dashwood C., Guzzetti F., Tier-based approaches for landslide susceptibility assessment in Europe, Landslides, vol. 10, pp 529-546, 2013;

[6] Hasekioĝulları G.D., Ercanoglu M., A new approach to use AHP in landslide susceptibility mapping: a case study at Yenice (Karabuk, NW Turkey), Nat Hazards, vol. 63, pp 1157-1179, 2012; 
[7] Komac M., A landslide susceptibility model using the Analytical Hierarchy Process method and multivariate statistics in perialpine Slovenia, Geomorphology, vol. 74, pp 17-28, 2006;

[8] Rozos D.E., Bathrellos G.D., Skillodimou H.D., Comparison of the implementation of Rock Engineering System (RES) and AHP methods, based on landslide susceptibility maps, compiled in GIS environment. A case study from the Eastern Achaia County of Peloponnesus, Greece, Environ Earth Sci, vol. 63, pp 49-63, 2011.

[9] Yalcin A., GIS-based landslide susceptibility mapping using analytical hierarchy process and bivariate statistics in Ardesen (Turkey): Comparisons of results and confirmations, Catena, vol. 72, pp 1-12, 2008.

[10] Armaș I., An analytic multicriteria hierarchical approach to assess landslide vulnerability. Case study: Cornu village, Subcarpathian Prahova Valley/Romania, Z Geomorphology, vol. 55, pp 209-229, 2011;

[11] Patriche C.V., Pîrnău R., Grozavu A., Roșca B., A comparative analysis of binary logistic regression and analytical hierarchy process for landslide susceptibility assessment in the Dobrovăț River Basin, Romania, Pedosphere, vol. 26/issue 3, pp 335350, 2016; 